\title{
Characteristics of convective snow bands along the Swedish east coast
}

\author{
Julia Jeworrek $^{1}$, Lichuan Wu ${ }^{1}$, Christian Dieterich ${ }^{2}$, and Anna Rutgersson ${ }^{1}$ \\ ${ }^{1}$ Department of Earth Sciences, Uppsala University, Uppsala, 75236, Sweden \\ ${ }^{2}$ Swedish Meteorological and Hydrological Institute, Norrköping, 60176, Sweden
}

Correspondence to: Anna Rutgersson (anna.rutgersson@met.uu.se)

Received: 26 September 2016 - Discussion started: 25 October 2016

Revised: 30 January 2017 - Accepted: 2 February 2017 - Published: 6 March 2017

\begin{abstract}
Convective snow bands develop in response to a cold air outbreak from the continent or the frozen sea over the open water surface of lakes or seas. The comparatively warm water body triggers shallow convection due to increased heat and moisture fluxes. Strong winds can align with this convection into wind-parallel cloud bands, which appear stationary as the wind direction remains consistent for the time period of the snow band event, delivering enduring snow precipitation at the approaching coast. The statistical analysis of a dataset from an 11-year high-resolution atmospheric regional climate model (RCA4) indicated 4 to 7 days a year of moderate to highly favourable conditions for the development of convective snow bands in the Baltic Sea region. The heaviest and most frequent lake effect snow was affecting the regions of Gävle and Västervik (along the Swedish east coast) as well as Gdansk (along the Polish coast). However, the hourly precipitation rate is often higher in Gävle than in the Västervik region. Two case studies comparing five different RCA4 model setups have shown that the Rossby Centre atmospheric regional climate model RCA4 provides a superior representation of the sea surface with more accurate sea surface temperature (SST) values when coupled to the ice-ocean model NEMO as opposed to the forcing by the ERA-40 reanalysis data. The refinement of the resolution of the atmospheric model component leads, especially in the horizontal direction, to significant improvement in the representation of the mesoscale circulation process as well as the local precipitation rate and area by the model.
\end{abstract}

\section{Introduction}

The roughness and temperature differences between land and water surfaces often lead to local sub-climates such as mesoscale circulation systems or stable and unstable conditions. For instance, during autumn and winter when the water surface temperature is still warmer than the average air temperature an unstable stratification develops in low levels since the ice-free water surface appears as a source of moisture and heat to the overlying air mass. As a result, mesoscale convective precipitation events like convective snow bands may develop.

Convective snow bands are also known and studied as lake effect snow (e.g. at the Great Lakes), cloud streets, horizontal convective rolls or vortices with solid precipitation. At the Swedish east coast, they are often referred to as a snow canon (snökanon). Convective snow bands develop commonly over the open water surface of lakes or seas when cold air approaches from the continent. Enhanced heat and moisture fluxes from the comparatively warm water body trigger shallow convection as the colder air mass travels across the sea. An unstable atmospheric boundary layer builds up and the formation of shallow convective clouds is favoured. Relatively strong winds can organize this convection into windparallel quasi-stationary cloud bands with moving individual cells. Depending on various factors such as the strength of the horizontal wind, the vertical wind shear or the shape of the coast (Andersson and Gustafsson, 1993), different snow band structures can form (Niziol et al., 1995). When the prevailing atmospheric conditions imply a strong development of convective snow bands, intense precipitation occurs locally where the snow bands hit the coast. The highest precipitation has, however, been shown to occur over the sea close 
to the coast (Andersson and Nilsson, 1990). The topographic changes from sea to land involve additional convergence and orographic lifting, which intensify the snowfall further. Since the circulation is organized in steady bands along the wind direction, usually only a limited area is affected by the snowfall. Thus, a reliable wind field forecast is crucial for a prediction of the hazard area.

Convective snow bands lead repeatedly to severe precipitation events in the cold season of the high mid-latitudes around the world. This phenomenon occurs frequently at several regions situated in high latitudes, including the Great Lakes (Kelly, 1986). However, even the Swedish east coast and the coastal regions along the Gulf of Finland frequently experience convective snow band events. The large amounts of snow along with strong wind speeds can cause serious problems for traffic, infrastructure, and other important establishments of society. Due to global warming it is in general expected that larger areas of lakes and inland seas will stay longer ice-free (IPCC, 2015). As a result, the occurrence of those convective snow band events may become more frequent as well as more intense.

We here investigate the ability of the numerical regional climate model RCA4 (Rossby Centre regional atmospheric model) to simulate snow bands, with the purpose of identifying the sensitivity of the results to the model resolution and surface forcing conditions and to derive climate statistics of the occurrence. Convective snow bands in the Baltic Sea area have been studied widely using a variety of methods for the Gulf of Finland as well as other parts of the Baltic Sea (e.g. by Andersson and Gustafsson, 1993; Andersson and Nilsson, 1990; Vihma and Brümmer, 2002; Mazon et al., 2015; Savijärvi, 2012, 2015). The focus of our study is on the performance of a regional climate model to represent convective snow bands affecting the Swedish east coast. This emphasis allows the determination of snow band conditions based on very specific atmospheric properties associated with lake effect snow for the region.

The large-scale synoptic situation leading to convective snow band development over the Baltic Sea can be very different. However, a strong pressure gradient over the Baltic Sea is required to guide cold air masses from the northnortheast over the warm water surface. Strong prevailing northeast winds with small vertical wind shear are unusual for this latitude, but they can result from a deep low-pressure system southeast of the Baltic Sea and/or indirectly by a local high-pressure development over the cold north of Scandinavia. Therefore, convective snow bands can occur in the Baltic Sea area, and furthermore along the north- and northeast-facing coasts of Estonia, Latvia, Poland, and even Germany.

Studies by Evans and Wagenmaker (2000), Niziol et al. (1995), Andersson and Gustafsson (1993), and Niziol (1987) provided evidence that convective snow bands occur under specific conditions. The most important element for the formation of snow bands is the thermal difference be- tween the water surface and the overlaying air (Mazon et al., 2015), which determines the extent of the essential heat and moisture fluxes. Therefore, it is necessary that a large part of the water surface is ice-free in order to ensure sufficient sensible heat release and evaporation from the sea. A partially frozen sea changes the coast line and affects the conditions for snow band developments considerably. Another important condition is the presence of instability to trigger convection. For the Great Lakes it has been observed that the minimum temperature difference between the water surface and the $850 \mathrm{hPa}$ level must be $13{ }^{\circ} \mathrm{C}$ to initiate convective snow bands without additional synoptic-scale forcing (Holroyd, 1971). This vertical temperature gradient matches approximately the dry adiabatic lapse rate. A larger value for the atmospheric lapse rate implies the presence of an absolute unstable layer within the lowest $850 \mathrm{hPa}$. A big thermal difference may furthermore enhance the moisture flux towards the air mass and support the formation of clouds and precipitation. The conditions for an intense development of convective snow bands are more favourable with increasing instability. However, the convection is vertically restricted. A capping subsidence inversion usually determines the height of the unstable boundary layer. This convective layer should extend at least $1 \mathrm{~km}$ above the surface in order to allow adequate convective cloud growth. Nevertheless, Niziol et al. (1995) indicate that large heat and moisture fluxes from the water surface can significantly lift and even erode the inversion layer.

The wind field throughout the boundary layer plays an essential role for the evolution of convective snow bands. The most common and severe snow bands are aligned parallel to a strong prevailing wind (type I snow bands defined by Niziol et al., 1995) larger than $10 \mathrm{~m} \mathrm{~s}^{-1}$ (Andersson and Nilsson, 1990). It should be noted that lower wind speeds of less than $5 \mathrm{~m} \mathrm{~s}^{-1}$ may also lead to the development of shorelineparallel cloud bands, initiated by a thermally driven landbreeze circulation (type IV snow bands defined by Niziol et al., 1995). A combination of wind speed and wind direction, and thus the distance and path that the air travels across the water surface, determines how much time an air mass of certain properties has to absorb heat and moisture from the water. A longer fetch allows a stronger development of the snow band. Laird et al. (2003) found for idealized cases that cloud bands form when the ratio between the wind speed and the fetch distance over the open water is between 0.02 and $0.09 \mathrm{~m} \mathrm{~s}^{-1} \mathrm{~km}^{-1}$. Accordingly, for a wind speed of $10 \mathrm{~m} \mathrm{~s}^{-1}$ the fetch distance has to be between 110 and $500 \mathrm{~km}$. Therefore, stronger winds require larger fetch distances.

The directional wind shear within the convective boundary layer is observed to be small for the time period of the snow band event. Niziol (1987) established a criterion for the likelihood of lake effect snow depending on the wind shear within the steering layer of the snow band (which determines approximately the first $50 \mathrm{hPa}$ above the ground up to $700 \mathrm{hPa}$ ). Thus, convective snow bands are likely to occur 
for a directional wind shear of less than $30^{\circ}$. At a directional wind shear between 30 and $60^{\circ}$ snow bands are possible to develop; however, beyond $60^{\circ}$ the band-like structure will break down.

Even the shape and the topography of the coast surrounding the water body can be essential for the snow band evolution. Andersson and Gustafsson (1993) investigated that the genesis areas for convective cloud bands are often bays at the "coast of departure". A convergence zone develops as two opposed land breezes meet in the centre of the sea. The secondary circulation system forces convection, which continues downwind as bands of convective rolls. When reaching the "coast of arrival", the convection can be enhanced by another land breeze raising the capping inversion. Snow bands tend to organize themselves parallel to a concave shaped shoreline. Islands that are located along the fetch disturb the heat and moisture flux from the sea to the air mass locally and can cause multiple bands to reorganize and merge or split up.

\section{Numerical model systems}

Case studies with high-resolution numerical weather prediction (NWP) models have been carried out successfully to represent convective snow bands. The present study, however, evaluates the potential of applying a regional climate model with relatively coarse resolution to conduct climatological studies for this mesoscale phenomenon. Performing simulations at a high resolution is computationally expensive and time consuming, and therefore it is less feasible to use a high-resolution NWP model at climatological timescales. An appropriate model for climatological studies of snow bands must balance computational expense and accuracy of the simulated physical processes. Case studies of different model configurations are therefore essential to evaluate the model's performance in order to be aware of potential weaknesses and to give a justified interpretation of the climatological results. In a regional climate model the information on the large-scale forcing is given at the lateral boundaries, and regional response to local conditions (like surface information) can be studied. We also use additional models coupled to the regional atmospheric model (RCA4) to study the importance of more accurate sea surface temperature (by using the ocean model NEMO) or impact of surface waves (by using the wave model WAM).

\section{$2.1 \quad \mathrm{RCA} 4$}

The Rossby Centre of the Swedish Meteorological and Hydrological Institute (SMHI) has been developing and applying climate models since 1997 (Jones et al., 2011). RCA4 is the latest version of their regional atmospheric climate model and it is run over many different Coordinated Regional Climate Downscaling Experiment (CORDEX) domains (Nikulin, 2013). The domain used in this study (illustrated in red in Fig. 1) covers Europe. RCA is based

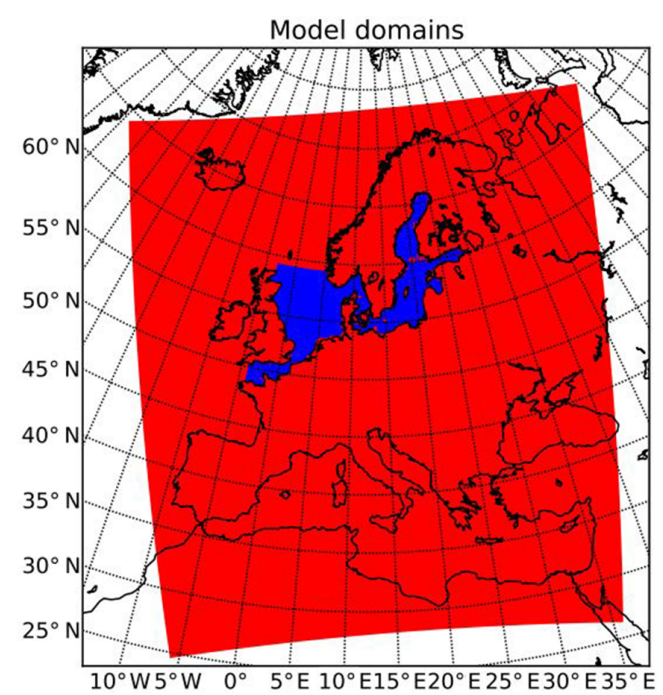

Figure 1. The domain of the NEMO model (in blue) embedded in the RCA European CORDEX domain (in red) (Dieterich et al., 2013).

on the operational numerical weather prediction model HIRLAM, although RCA was developed to simulate the atmosphere based on climatological timescales. The foundation of this hydrostatic model are primitive equations using terrain-following hybrid vertical coordinates and a rotated longitude-latitude grid. The original model employed time steps of $15 \mathrm{~min}, 40$ model layers as vertical coordinates and a spherical resolution of $0.22^{\circ}$, which is corresponding to about $25 \mathrm{~km}$ horizontal grid spacing (Dieterich et al., 2013). Initial and lateral conditions for parameters like ice cover, sea surface temperature (SST) or wind speed are provided to the model every 6 hours by the interpolated ECMWF reanalysis data ERA-40 (Uppala et al., 2005).

\subsection{RCA4-NEMO}

The atmosphere-ocean interaction is of great importance for the atmosphere's properties and dynamics as well as the entire Earth's climate system. The SST is a crucial factor for the accurate representation of the development of convective snow bands. The Nucleus for European Modelling of the Ocean NEMO (Madec, 2012) is an ice-ocean model based on primitive equations. Its domain covers the North Sea and the Baltic Sea and is shown in blue in Fig. 1. The boundaries at the northern North Sea and the English Channel are kept open and take information of the Atlantic Ocean outside the NEMO-Nordic domain into account (Dieterich et al., 2013). In comparison with the default settings of the RCA4 model, NEMO-Nordic has a very high resolution with a horizontal grid spacing of two nautical miles, corresponding to circa $3.7 \mathrm{~km}$, and 56 geopotential levels at the vertical scale (Dieterich et al., 2013). NEMO can be coupled to RCA in order to exchange information at the interfaces between air and sea 
or ice. The ice-ocean model provides parameters such as ice fraction and albedo as well as SST to the atmospheric model. In turn RCA4 communicates heat, freshwater, and momentum fluxes to the NEMO model (Wang et al., 2015). The coupling of two independently developed model components such as RCA4 and NEMO can be realized by OASIS3 - the Ocean Atmosphere Sea Ice Soil Simulation Software. This coupler was developed by PRISM, the Project for Integrated Earth System Modelling and is commonly used in the climate modelling community (Valcke, 2013).

\subsection{RCA4-WAM}

Waves have an impact on the roughness length at the water surface, affecting in return the low-level wind field as well as the heat fluxes. RCA4 has been used in connection to a wave model in order to test the sensitivity of this interrelationship. The WAve Model (WAM) is a third-generation full-spectrum prognostic wave model using the basic transport equation (WAMDI Group, 1988), which can be used for an atmosphere-wave coupled system. The WAM model explicitly solves the energy balance equation in order to gain the evolution of the wave spectrum (Janssen, 2004). The European Centre for Medium-Range Weather Forecasts (ECMWF) has been running a coupled system of WAM in communication with an atmospheric component operationally since 1998 (ECMWF, 2016). For the purpose of coupling, WAM and RCA4 have the same resolution and time step frequency in this study. Here the WAM model component is treated as a subroutine which is called by RCA4 with every time step communicating the essential information between the model components. The WAM model provides RCA4 with wave information in exchange for wind field data from the atmospheric model. The important wave data for the RCA model is obtained by a two-dimensional ocean wave spectrum and may involve parameters like wave height and period as well as roughness length. The applied coupled RCA4-WAM setup is similar to that described by Wu et al. (2015) and Rutgersson et al. (2012) only exchanging the roughness length.

\section{Method and outline}

In order to give a good representation of the Baltic Sea, regional models with high resolution are essential to reproduce topographical features and substantial processes. In connection with the investigation of the mesoscale processes determining convective snow band events, this study was carried out in two parts: the statistical analysis of snow band events based on an 11-year RCA4 dataset and the evaluation of the use of different regional climate model systems.

First, the atmospheric regional climate model RCA4 was used in a high resolution to simulate the atmosphere over the 11-year time period from 2000 to 2010 with a spin-up of 2 months. The horizontal RCA4 resolution was set to $0.16^{\circ}$, which corresponds to approximately $18 \mathrm{~km}$ grid spacing. In order to keep the model numerically stable, the time step is $10 \mathrm{~min}$. Based on the criteria listed in Sect. 1, days of convective snow band conditions were selected and statistically analysed with respect to the season and the strength of the snowfall. The applied criteria are summarized in Table 1 and distinguish with different threshold values between moderate and favourable conditions for snow band development reflecting the local as well as the large scale for the occurrence of precipitation related to convective snow bands. The investigation is focused on convective snow bands which develop over the Baltic Sea and lead to snowfall at the Swedish coast. The criteria were therefore applied to either the Baltic Sea area as seen in Fig. 2a or the specified precipitation sector as seen in Fig. 2b.

In the second part of this study, two case studies are presented, comparing the atmospheric properties simulated by five different model setups in order to give an assessment of the specific model performance concerning snow bands. An overview over the five model systems is given in Table 2. The regional atmospheric climate model RCA4 has been used with resolution of 40 vertical model layers and $0.22^{\circ}$ (about $25 \mathrm{~km}$ ) horizontal grid spacing with a spin-up time of approximately 2 months ahead of the snow band event. A coupled simulation of the RCA4 with the ocean model NEMO was carried out to investigate the impact of the SST. In order to provide enough time for adjustment between the models, a spin-up of almost 2 years was used. The two components in the coupled system of RCA4 and WAM are identical with regard to horizontal resolutions and time steps, while WAM provides the RCA model with a sea surface roughness corresponding to the atmospheric wind field above. The final two experiments were performed using RCA4 simulations with increasing resolutions either in horizontal spacing or in vertical direction. The horizontal resolution was refined from 0.22 to $0.11^{\circ}$ (about $12.5 \mathrm{~km}$ ) and the 40 model layers of the original RCA4 set-up were increased in a different run to 62 layers. A spin-up time similar to the RCA simulation was used. The higher resolution, however, requires a lower time step, which was therefore decreased from 15 to $5 \mathrm{~min}$.

\section{Results}

\subsection{Analysis of an 11-year RCA4 dataset}

The atmospheric conditions which favour the development and maintenance of convective snow bands show a recurrent pattern in the Baltic Sea region. In order to select a day as convective snow band event the criteria presented in Table 1 must be fulfilled within the respective area (defined as in Fig. 2).

The high-resolution RCA4 simulation from 2000 until 2010 reproduces a total of 121 days with these criteria fulfilled; 49 of these days are within the limits of the stricter thresholds describing favourable conditions for snow band 
(a)

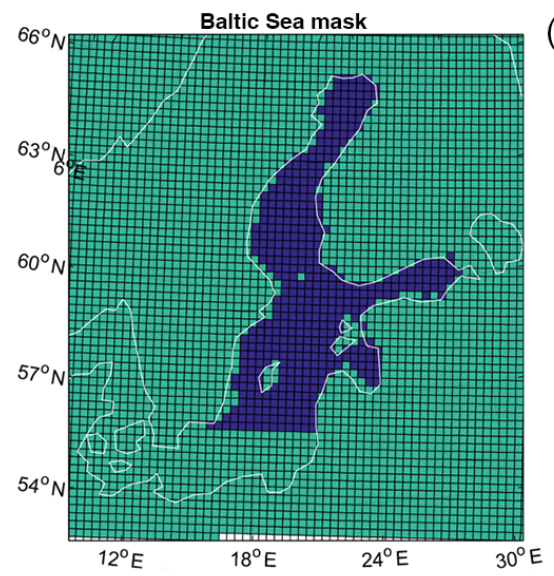

(b)

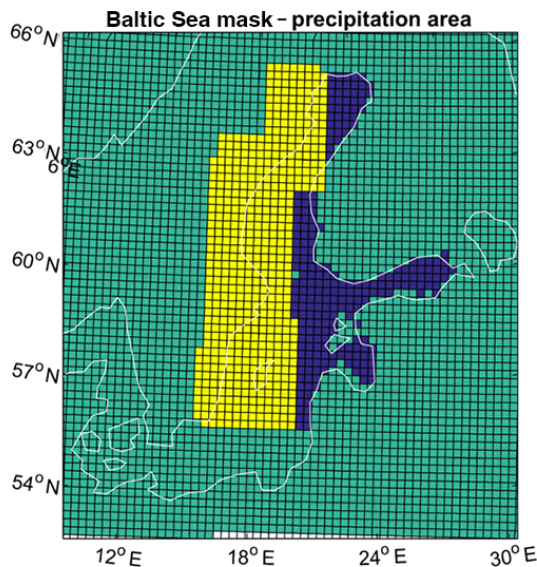

Figure 2. Baltic Sea area (in blue, a) and the precipitation area (in yellow, b) considered for the criteria for the selection of days with convective snow band conditions (compare to Table 1).

Table 1. Criteria for the selection of days with moderate to favourable atmospheric conditions for convective snow bands. The Baltic Sea area and precipitation area are defined in Fig. 2.

\begin{tabular}{|c|c|c|c|}
\hline Region & Parameter & Weak criteria & Strong criteria \\
\hline \multirow[t]{6}{*}{ Baltic Sea area } & Max $10 \mathrm{~m}$ wind speed & \multicolumn{2}{|c|}{$>10 \mathrm{~ms}^{-1}$} \\
\hline & Mean $2 \mathrm{~m}$ temperature & $<8^{\circ} \mathrm{C}$ & $<5^{\circ} \mathrm{C}$ \\
\hline & $\begin{array}{l}\text { Max temperature difference (between } \\
\text { surface and } 850 \mathrm{hPa} \text { ) }\end{array}$ & $>13^{\circ} \mathrm{C}$ & $>15^{\circ} \mathrm{C}$ \\
\hline & $\begin{array}{l}\text { Mean wind shear (between } 700 \text { and } \\
975 \mathrm{hPa} \text { ) of } 50 \% \text { of the Baltic Sea area }\end{array}$ & $<60^{\circ}$ & $<30^{\circ}$ \\
\hline & Mean wind direction (at $900 \mathrm{hPa}$ ) & \multirow{2}{*}{\multicolumn{2}{|c|}{$\begin{array}{c}\text { between } 0 \text { and } 90^{\circ} \\
>1000 \mathrm{~m}\end{array}$}} \\
\hline & Max boundary layer height & & \\
\hline \multirow{2}{*}{$\begin{array}{l}\text { Precipitation } \\
\text { area along the } \\
\text { Swedish coast }\end{array}$} & Max precipitation & $>0.5 \mathrm{~mm} \mathrm{~h}^{-1}$ & $>1 \mathrm{~mm} \mathrm{~h}^{-1}$ \\
\hline & Max snowfall & $>1.5 \mathrm{~mm} \mathrm{~d}^{-1}$ & $>0.5 \mathrm{~mm} \mathrm{~h}^{-1}$ \\
\hline
\end{tabular}

formation. Correspondingly, favourable atmospheric conditions occur for a strong development of convective snow bands over the Baltic Sea on average 4.5 days a year. When including the remaining cases which meet the weaker criteria, a total average of 11 days per year is obtained. Figure 3 displays the distribution of the cases per year and month. It is seen that the total number of days varies between 5 and 22 per year. The months of November and December show the highest frequency of days with atmospheric conditions favourable for snow band development (Fig. 3b).

The maximum $10 \mathrm{~m}$ wind speed of all selected snow band days is on average $13.3 \mathrm{~m} \mathrm{~s}^{-1}$. The mean wind direction varies between all cases approximately from 0 to $65^{\circ}$. Hence, north and northeast wind is most common. Easterly wind, which could generate snow bands from the Gulf of Finland (Mazon et al., 2015), is surprisingly not seen for any period. The mean wind shear over half of the Baltic Sea area is small for all days. Most cases represent mean wind shear values of even less than $10^{\circ}$. The maximum temperature gradient of the lowest $850 \mathrm{hPa}$ is on average $18^{\circ} \mathrm{C}$ and the maximum boundary layer height over the Baltic Sea is usually around $1.7 \mathrm{~km}$.

The largest impact of convective snow bands on the public life is due to the heavy snowfall. The intensity of a snow band event may be defined by the consequent amount of its precipitation at the coast. The scale of the given snowfall values refers to the volume that the snow would possess in liquid, rather than solid form. This snowfall parameter, however, does not include precipitation in liquid form, but only solid snowfall at a scale of melted ice. As an approximate relationship it is reasonable to assume that one millimetre of melted snow corresponds roughly to $1 \mathrm{~cm}$ of gained snow depth, although the density of the snow depends strongly on parameters like temperature and age of the snow (Dubé, 2003). The selected days indicate a maximum snowfall rate between 0.2 and $3 \mathrm{~mm} \mathrm{~h}^{-1}$. While most values were smaller than $2 \mathrm{~mm} \mathrm{~h}^{-1}$, only two outliers in January and February 2007 attained values of approximately 2.6 and $2.9 \mathrm{~mm} \mathrm{~h}^{-1}$. 
Table 2. Overview of the model experiments used for the analysis of an 11-year dataset and the model evaluation based on two case studies.

\begin{tabular}{lllrr}
\hline & \multicolumn{1}{c}{ Experiments } & Abbreviation & Horizontal resolution & Vertical levels \\
\hline 11-year dataset & RCA4 with increased horizontal resolution & & $0.16^{\circ}$ & 40 \\
\hline Case studies & RCA4 & RCA & $0.22^{\circ}$ & 40 \\
& RCA4-NEMO & RCA-NEMO & $0.22^{\circ}$ & 40 \\
& RCA4-WAM & RCA-WAM & $0.22^{\circ}$ & 40 \\
& RCA4 with increased horizontal resolution & RCA high horiz & $0.11^{\circ}$ & 40 \\
& RCA4 with increased vertical resolution & RCA high vert & $0.22^{\circ}$ & 62 \\
\hline
\end{tabular}
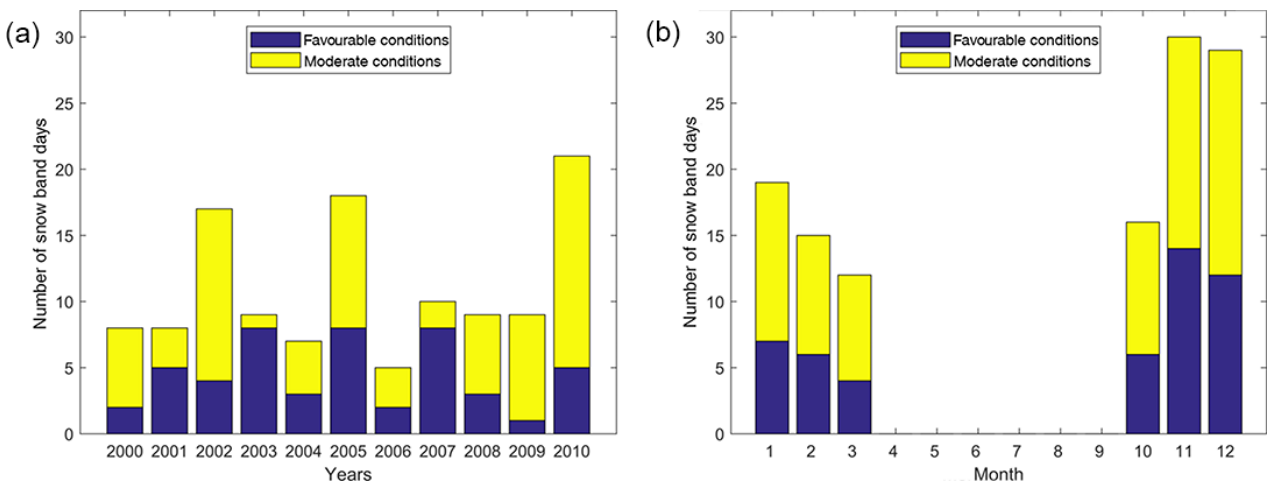

Figure 3. Number of snow band days fulfilling the applied criteria per year (a) and month (b).

The mean value of the maximum snowfall rate of each day amounts to $0.8 \mathrm{~mm} \mathrm{~h}^{-1}$. Accumulated over the day, the snowfall varies between 1.5 and $17 \mathrm{~mm} \mathrm{~d}^{-1}$, with a total mean of $5.8 \mathrm{~mm} \mathrm{~d}^{-1}$.

The regions affected by the precipitation of convective snow bands in the Baltic Sea area can be seen in Fig. 4. These data represent the hourly accumulated snowfall as an average value of all selected days (Fig. 4a) as well as only for the days which meet the criteria for favourable conditions (Fig. 4b). The precipitation reference sector considered for the selection criteria (as defined in Fig. 2b) is framed in black. However, the figures represent a sector that exceeds the precipitation area in order to observe whether other regions are also affected by enhanced precipitation on the same days. The average snowfall rate results from the total snowfall of the selected days (of favourable or favourable and moderate atmospheric conditions for convective snow bands) normalized by the number of days with positive snowfall at a specific location. Accordingly, along the Swedish coast two separate regions are mainly pronounced by a large average daily precipitation rate. The concavely shaped shore near the Swedish town Gävle represents the most intense snowfall within the precipitation sector with up to $3 \mathrm{~mm} \mathrm{~d}^{-1}$ on average for the days of favourable conditions. The area around the town Västervik at the Swedish east coast, west of the island Gotland, also displayed a large area of high average snowfall at around $2.5 \mathrm{~mm} \mathrm{~d}^{-1}$. In addition, the Swedish island Gotland indicates pronounced precipitation. Outside of the precipi- tation sector another hotspot appears in the Gdansk region at Poland's north coast. The area of high average snowfall reaches values up to $2.5 \mathrm{~mm} \mathrm{~d}^{-1}$. Around the Baltic Sea it can be observed that all coasts which are facing north, northeast, or east experience enhanced snowfall for the selected snow band days.

A similar picture is obtained regarding the frequency of favourable conditions for convective snow bands. While the selection criteria for favourable conditions were fulfilled 4.5 times a year on average, approximately once per year the Gävle region received snowfall rates larger than $5 \mathrm{~mm} \mathrm{~d}^{-1}$ (Fig. 5). Snowfall of more than $10 \mathrm{~mm} \mathrm{~d}^{-1}$ due to convective snow bands occurs approximately every third year. The hourly precipitation rate is often higher in Gävle than around Västervik (Fig. 6). Although lower hourly snowfall rates between 0.5 and $1 \mathrm{~mm} \mathrm{~h}^{-1}$ occur in the Västervik region more often (about every 8 months) and cover a larger region than in Gävle (where they occur about once a year), higher snowfall rates of larger than $1 \mathrm{~mm} \mathrm{~h}^{-1}$ are more frequent in Gävle (approximately once every one and a half years) than in Västervik (where this happens only every third year). Outside of the precipitation sector the area near Gdansk indicates snowfall larger than $5 \mathrm{~mm} \mathrm{~d}^{-1}$ about every one and a half years.

\subsection{Case studies}

Two different cases have been selected to study the sensitivity of the model setup. Five different RCA4-based model setups are used (Table 2) considering the atmospheric con- 
(a)

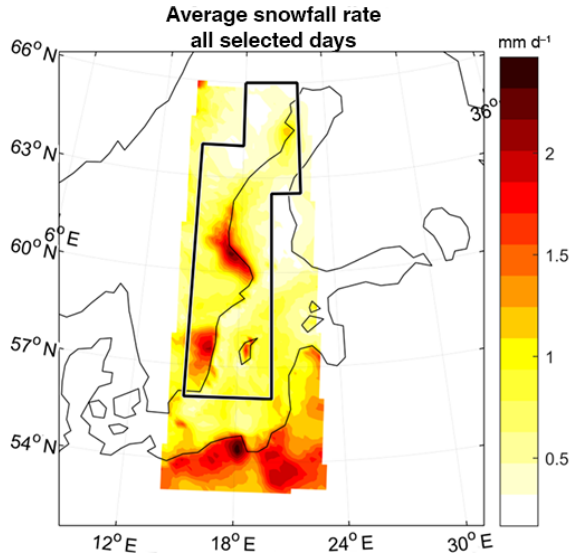

(b)

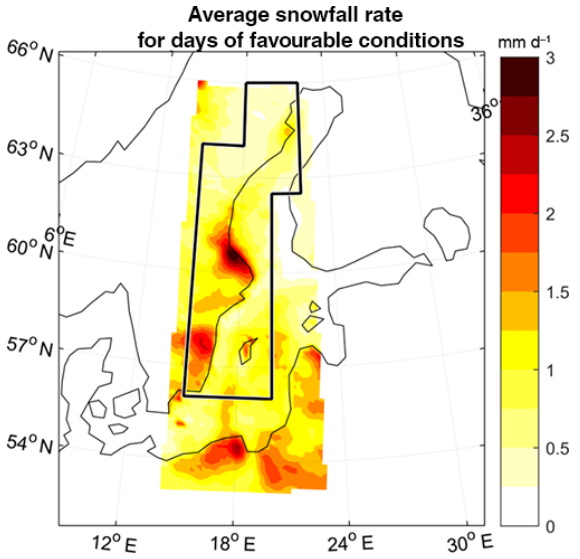

Figure 4. Average snowfall rate for all 121 selected days (a) and for the 49 days of favourable atmospheric conditions for convective snow bands (b) from 2000 to 2010 normalized by the frequency of positive snowfall.

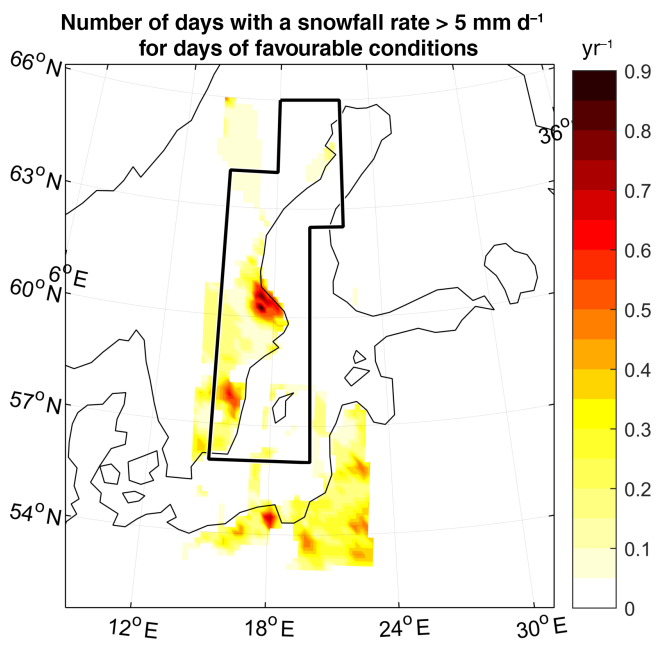

Figure 5. Frequency of occurrence for favourable atmospheric conditions with convective snow bands causing a snowfall rate greater than $5 \mathrm{mmd}^{-1}$.

ditions of convective snow bands. Case 1 concerns a wellstudied event in early December 1998 that caused $130 \mathrm{~cm}$ solid snowfall within 3 days in the Swedish town Gävle (SMHI, 2015). The less intense case 2 occurred in early February 2001 and had similar synoptic conditions. Cold air was transported from Finland over the Gulf of Bothnia causing extreme snow precipitation at the Swedish coast close to Gävle. While the wind direction in case 1 remained consistent over several days by accumulating snowfall at a restricted area around Gävle, in case 2 the wind direction turned slightly and distributed the precipitation more along the Swedish coast. Both cases lasted 3-4 days, and for a better understanding of the evolution of the atmospheric situation approximately 1-day ahead and 1-day after the snow band have been taken into account for the investigation.
All model systems show similar behaviour for the wind field development. The maximum $10 \mathrm{~m}$ wind speed over the Baltic Sea increases rapidly with the beginning of the convective snow band event and slowly decreases in the following days. Due to the wave feedback through the wind-wave interaction as well as the nonlinear wave interaction in the two-dimensional wave spectrum calculation of the roughness length in the WAM model, this development showed in both cases a delay by several hours for the RCA-WAM simulation relatively to the other models. The comparison with SMHI station measurements indicates that most models underestimated the $10 \mathrm{~m}$ wind speeds at the Swedish coast. The best representation of the observational wind data has been obtained by the RCA model with increased horizontal resolution. The mean wind shear between 975 and $700 \mathrm{hPa}$ was in both cases around $30^{\circ}$ for the considered area of the Gulf of Bothnia. Case 2 indicates higher wind shear values for the days before and after the snow band event.

The air temperature field indicates for all models clearly that the Baltic Sea serves as a heat source to the air above. But due to the approaching cold air mass the temperature over the Gulf of Bothnia decreases rapidly. In case 1 the maximum $2 \mathrm{~m}$ temperature decreases within 2 days by $4{ }^{\circ} \mathrm{C}$; in case 2 it decreases even by $8^{\circ} \mathrm{C}$. Between all models RCA-NEMO simulated systematically higher $2 \mathrm{~m}$ temperatures, owing to a higher SST.

For the high-resolution RCA setups as well as the RCAWAM the ice cover and SST is provided to the RCA model by the ECMWF reanalysis data ERA-40. The spectral resolution of ERA-40 is T159, which corresponds to $1.125^{\circ}$ or approximately $125 \mathrm{~km}$ (Advancing Reanalysis, 2016). Hence, the sea surface input based on ERA-40 has a coarser resolution than the original RCA itself. Alternatively, the iceocean model component NEMO simulates its own SST in a much higher resolution (see Sect. 3.2) and can represent local features in more detail. When comparing the SSTs between ERA-40 and NEMO interpolated to the original RCA 
(a)

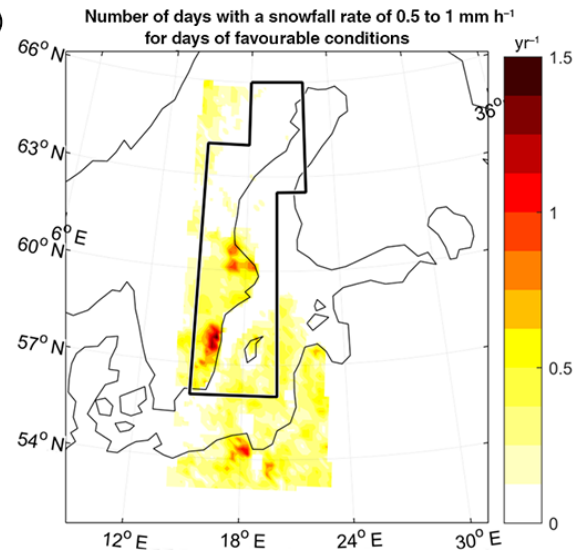

(b)

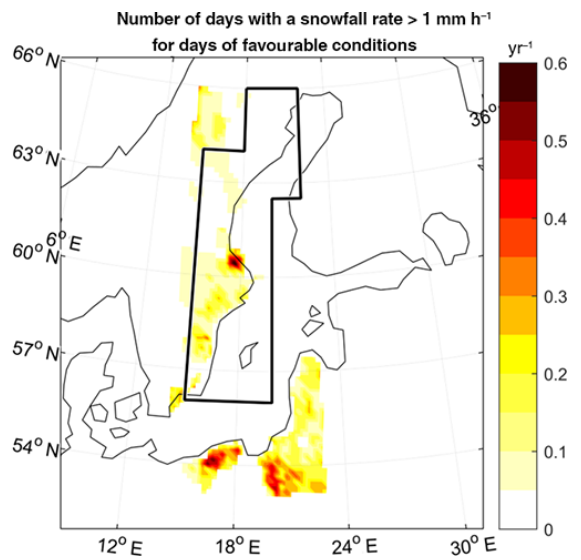

Figure 6. Frequency of occurrence of convective snow bands fulfilling the selection criteria for favourable atmospheric conditions (see Table 1) causing a maximum snowfall rate between 0.5 and $1 \mathrm{~mm} \mathrm{~h}^{-1}$ (a) and greater than $1 \mathrm{~mm} \mathrm{~h}^{-1}$ (b).

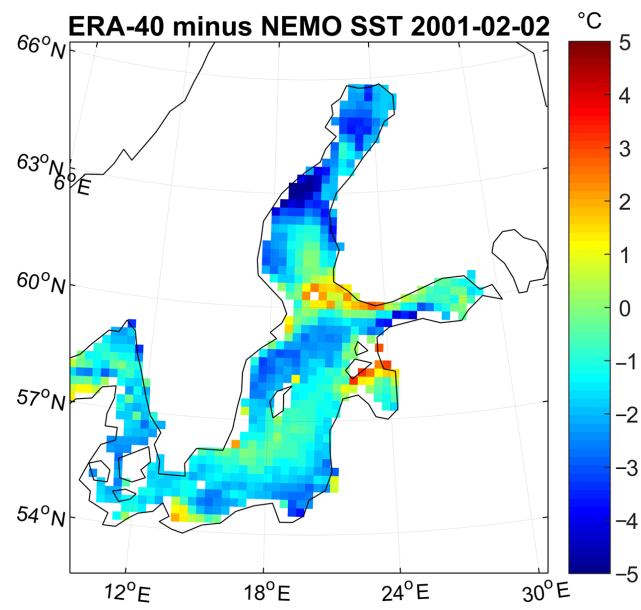

Figure 7. Difference map of the SST by ERA-40 and NEMO for 1 day of case 2 .

resolution, the NEMO SST resulted in generally higher values for both cases (see Fig. 7 for case 2). Only in the straits where the Baltic Sea is shallow is the SST difference between ERA-40 and NEMO small and at some locations even positive. However, the region of interest, the Gulf of Bothnia, shows in both cases significant differences. NEMO obtained up to $5{ }^{\circ} \mathrm{C}$ higher SSTs compared to ERA-40. The OISST data (NOAA, 2016), which are a result of the combination of measurements from satellites, ships, and buoys, indicated better agreement with the NEMO than the ERA-40 data. In the Gulf of Bothnia, the NEMO SST was in some locations around $1.5^{\circ} \mathrm{C}$ warmer than the OISST where the ERA-40 SST is up to $4{ }^{\circ} \mathrm{C}$ colder. Also, the development of sea ice cover is better represented by the NEMO model.

The SST is furthermore associated with the heat fluxes over the water surface. Accordingly, it is not surprising that the RCA-NEMO model represents the highest heat fluxes among the models for both sensible and latent heat over the
Gulf of Bothnia (Fig. 8). However, both case studies show that the RCA-NEMO heat fluxes agree well with all other models before the snow bands arise. The difference develops with the initial occurrence of the snow bands. All models represent an increasing sensible and latent heat flux development throughout the convective snow band event. The maximum heat fluxes are reached at a later stage of the evolution when the cloud bands start to dissolve again. The magnitude of the heat fluxes in the February case has been larger than in the December case. Similar to the temperature change, the evolution for the heat fluxes was also more rapid in case 2 .

The increased wind speeds and heat fluxes during the convective snow band event also cause the boundary layer height to rise. Based on the investigation of the two cases it has been observed that RCA-NEMO represents comparatively high boundary layer heights, while the RCA model with high horizontal resolution tends to give a shallower boundary layer (see Fig. 9). Although case 1 was an intense event the mixed layer height barely exceeds $1 \mathrm{~km}$, which has been defined as a threshold by the criteria in Sect. 2 .

Depending on the strength of the convective snow band, the amount of the total precipitation can vary vastly. A slight turning of the wind may furthermore lead to a distribution of the lake effect snow along the coast rather than the accumulation in one restricted area. Case 1 indicated a significantly greater accumulation of precipitation than case 2 , partly due to the consistent wind direction. The hourly precipitation of case 1 has however been more intense for a longer period of time. Regardless, for both cases the highresolution RCA models as well as the RCA-NEMO system indicate considerably higher precipitation rates than the original RCA or RCA-WAM. The $48 \mathrm{~h}$ accumulated total precipitation of case 2 reached up to $20 \mathrm{~mm}$ and can be compared for the different models in Fig. 10. In case 1 the precipitation of 2 days went even up to $45 \mathrm{~mm}$. Very remarkable were the results of the RCA simulation with increased horizontal resolution. The local maxima reach significantly higher values 

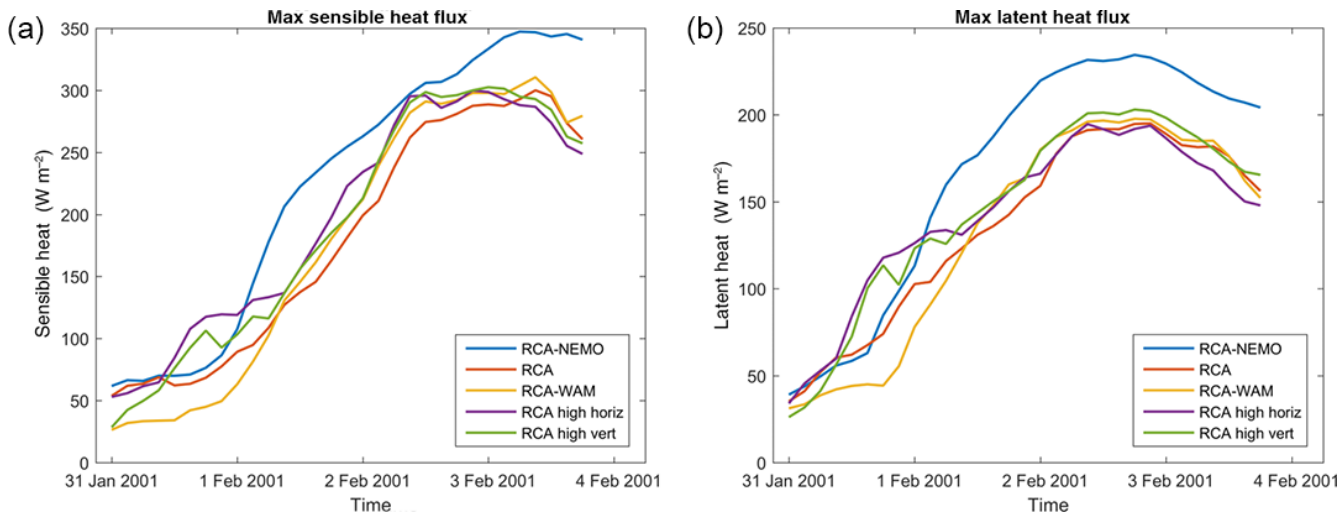

Figure 8. Maximum sensible heat flux (a) and maximum latent heat flux (b) over the Gulf of Bothnia for the time period of case 2.

(a)

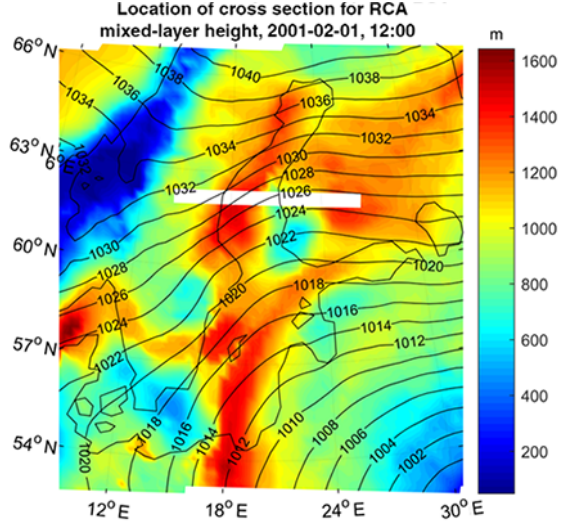

(b)

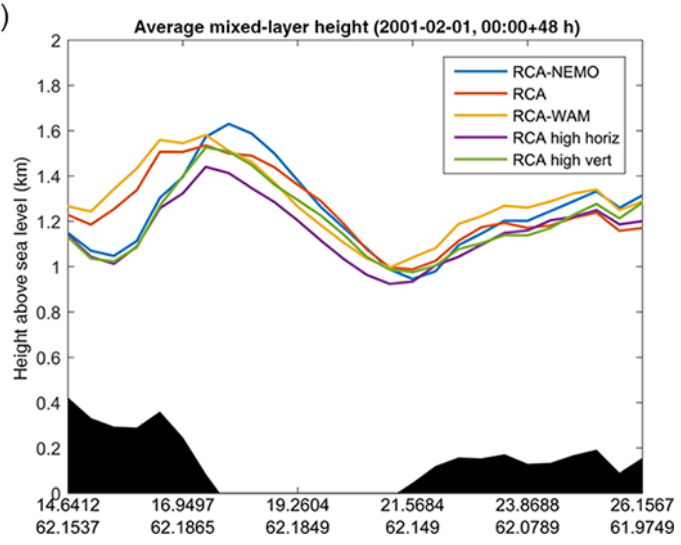

Figure 9. Boundary layer height horizontally for RCA (a) and the 2-day mean in a cross section for all models (b) for case 2.

and the confined precipitation area is represented in more detail. When comparing the model performance for the location of a weather station in Gävle with the measured precipitation, as in Fig. 11, it is clear that all models have difficulties in representing the exact time and location of the snowfall. For case 1, almost all models underestimate the actual precipitation. Only the RCA model with high horizontal resolution exceeds the measurements for 1 day. In case 2 , on the other hand, all models represent maximum precipitation rates at a time period that did not show any precipitation in the measurement data, while the measured precipitation showers in Gävle were not recognized by the models.

\section{Discussion}

The simulations by RCA and RCA-WAM resulted in a rather weak development of the convective snow bands and the comparison with observational data showed that the atmospheric conditions were often underestimated by these two models. The coupling of the atmospheric RCA model with the wave model component WAM employed a different roughness length computation at the sea. Hence, the largest impact was observed on the wind field. The magnitude of the maximum $10 \mathrm{~m}$ wind speed reaches similar values; however, the RCA-WAM model possesses a time shift due to the wave feedback on the roughness length and wind speed. With regard to all other investigated parameters, RCA and RCAWAM show very similar results and the different roughness length calculation due to the coupling of RCA and WAM has a negligible impact on the atmospheric conditions describing convective snow band events.

The coupled atmosphere-ocean system RCA-NEMO benefited clearly from the high resolution SST of the NEMONordic component. The reanalysis ERA-40 data which otherwise provided the uncoupled RCA model with the SST had a coarser resolution than the original RCA itself. For water bodies of the size of the Baltic Sea, this resolution is insufficient and the quality of the simulation is impaired as local extremes cannot be represented. The interpolated ERA-40 SST shows a negative bias towards the NEMO SST as well as independent datasets such as OISST. The difference is significant with up to $5^{\circ} \mathrm{C}$ between ERA-40 and NEMO. While the NEMO simulated SST was shown in some locations to be slightly higher than the OISST data, it provided a better representation of the sea surface properties than ERA-40. The higher SST of the RCA-NEMO model caused furthermore 

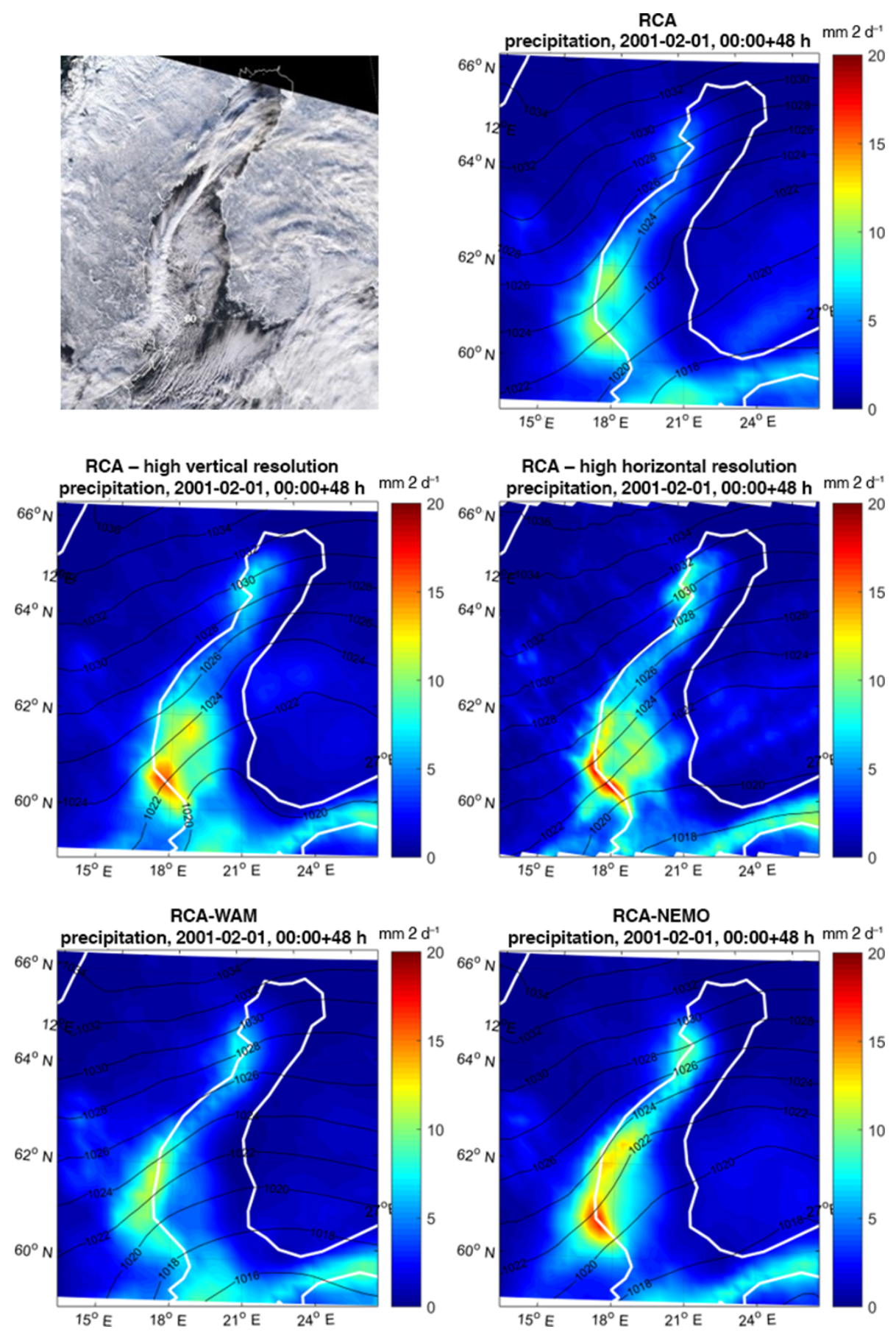

Figure 10. The 2-day accumulated total precipitation of all models for case 1 in comparison and a cropped satellite image of 1 February 2001 (MODIS, 2016).

larger heat fluxes and it increased the instability through a larger temperature difference within the lower layers resulting in an enhanced convection and a higher boundary layer height and finally, larger local precipitation rates.

A high resolution is of great importance when it comes to the regional modelling of mesoscale high-impact events. Increasing the resolution of the atmospheric RCA model re- sulted in a great improvement for the model performance. Both high-resolution simulations indicate larger values for the local maximum of the $10 \mathrm{~m}$ wind speeds over the Gulf of Bothnia. The best agreement with observational data, however, was obtained by the RCA model of increased horizontal resolution. Although the temperature and heat fluxes did not show any impact from an increased resolution in any di- 
(a)

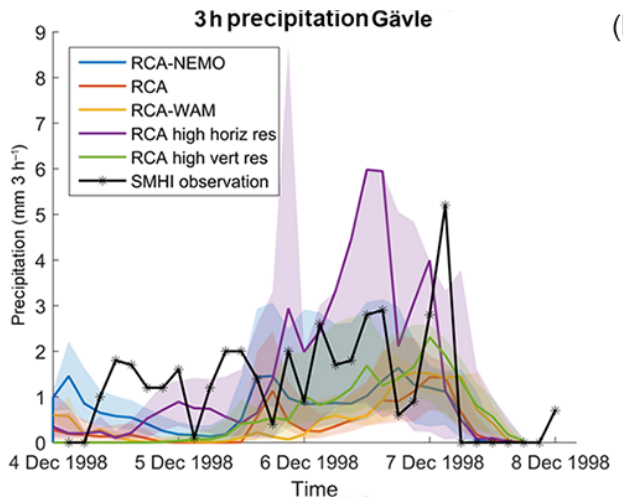

(b)

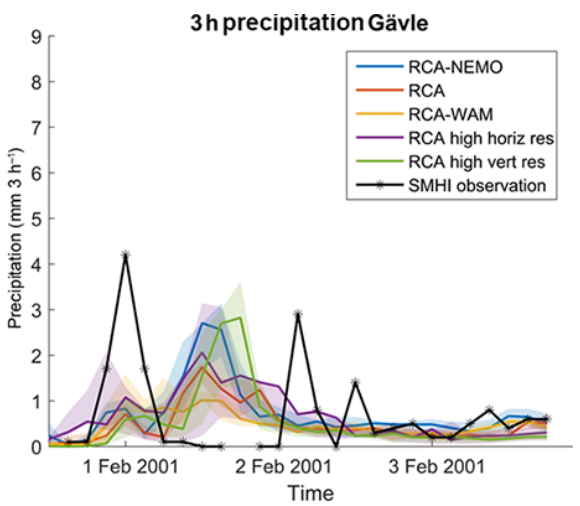

Figure 11. Time series of the precipitation measurements of the SMHI station in Gävle in comparison with the model results for this location. The solid line shows the model simulation at the closest grid point to the measurement site and the shaded area indicates the variation of this result according to the directly neighbouring grid points.

rection, the high horizontal resolution RCA was able to represent the mesoscale atmospheric circulation process associated with convective snow bands in more detail and resolved the local precipitation rate and area more precisely when compared to the other models.

Finding a method to select convective snow band events is not straightforward. Even though the atmospheric conditions are typical and can be described by certain criteria, the thresholds applied imposed a larger impact on the number of days which are selected. Although the criteria themselves were chosen based on references describing snow bands developing in other regions of the world, they are generally valid and the specific values for the selection were adjusted for the Baltic Sea region. The determination of two different categories distinguishing between weak and moderate conditions hints at a need to be more careful with the pool of days fulfilling only weak conditions. Since convective snow bands arise from cloud bands that may initially not give any precipitation, it is not always clear how to define the transition and where to set the threshold for heavy precipitation due to snow bands. The average precipitation did not appear very intense, as some days have been selected with rather low snowfall rates of snow bands which could not have developed as strongly. According to the results of the case studies, the RCA model often underestimates the exact amount of precipitation. The increased resolution improves the results on the representation of the snow bands; however, for a long dataset of 11 years it is very computationally intensive to run the simulations in such a high horizontal resolution as was done in the case studies. Also, the use of the ERA-40 data as sea surface input has shown its drawbacks, and caused the RCA model to simulate snow bands in a less intense evolution. The exact amount of the snowfall and its return period should therefore be interpreted with caution. However, the result for the distribution and the relative amount of the snowfall can be understood in a qualitative rather than a quantitative sense. The Gävle region possessed the largest average snowfall rates and the shortest return periods for comparatively high hourly snowfall rates as a result of snow bands developing over the Gulf of Bothnia. It seems natural that convective snow bands which require a cold air outbreak over the warmer sea will develop more frequently in the most northern part of the Baltic Sea. The shape of the Gulf appears furthermore conducive to the generation of convergence zones for the initial formation and the bay-shaped coast in the Gävle region enhances the precipitation due to orographic forcing once again. The snow precipitation occasionally reaches $100 \mathrm{~km}$ inland; however, the most intense lake effect snow falls approximately within a radius of $50 \mathrm{~km}$.

Northeast winds also often lead convective snow bands to the Västervik region; however, the average snowfall here is not as intense nor as frequent. Convective snow bands occur often in multiple band structures and it is common that various regions along the coast are affected by the lake effect snow when the atmospheric conditions are favourable in a large area. Hence, the Gdansk region was also perceived to experience convective snow bands on the same days as the Swedish coast, when all criteria were fulfilled as for convective snow bands along the Swedish coast (see Table 1 applied to the regions represented in Fig. 2).

Since convective snow bands occur in different strengths around the year, a statistical analysis as performed in the first part of this study must define the range of snow band criteria depending on their intensity. The present study includes snow bands that caused moderate snowfall. However, in order to investigate stronger snow band events with hazardous consequences a longer period of time should be studied with stricter criteria for the precipitation since their occurrence it not as frequent. 


\section{Conclusions}

The investigation of an 11-year RCA4 climate model dataset indicated the heaviest and most frequent lake effect snow due to convective snow bands in the Baltic Sea area affecting the Gävle region. The Västervik region at the Swedish coast and even the Gdansk area at the Polish coast also experienced enhanced snowfall on days of favourable atmospheric conditions for snow bands. When including days of moderate conditions for convective snow band development, a total of 11 days per year on average results. Most convective snow band events occur in the months of November and December, when the sea surface is still warm from the summer and the cold air approaches frequently from the cold Finnish land.

The application of RCA4 in different model setups has indicated for the two case studies that any of the investigated RCA4 model configurations simulate the atmospheric conditions for convective snow bands and fulfil the criteria established in previous research. Nevertheless, significant differences have been observed between the different model systems.

The RCA and RCA-NEMO model varied largely due to the different SST input provided by coarse reanalysis data or the high-resolution ocean model respectively. The coupled RCA-NEMO model provided a superior representation of the sea surface with significantly higher SST values when comparing with the ERA-40 data. The direct impact of the higher NEMO SST on the heat fluxes and convective development manifests itself through a more intense convective snow band development and higher local precipitation rates. Even if on a larger scale all models agree well on the overall precipitation area, the exact location on a smaller scale as well as the amount and time of the snowfall remain a challenge. The models differed to a great extent in the amount of accumulated precipitation. The largest precipitation rates were given by the two high-resolution models as well as the atmosphereocean model.

Since the atmosphere-ocean interaction is of great importance for the regional climate modelling of events like convective snow bands, the coupling with the high-resolution ocean model NEMO is advantageous compared with the use of the coarse reanalysis data used in the original RCA model. Moreover, the increased resolution of the atmospheric RCA model had a positive impact on the model results. The high horizontal resolution led to an especially significant improvement in the representation of the cloud bands, the precipitation area, as well as the wind speed. Based on the investigation of the two cases the use of a coupled atmosphereocean system in connection with a high horizontal resolution of the atmospheric component is suggested for a more accurate representation of convective snow bands in regional climate models.
Data availability. The data used in this study can be acquired by contacting the corresponding author.

Competing interests. The authors declare that they have no conflict of interest.

Acknowledgements. This work was done within the Centre of Natural Disaster Science (CNDS), Uppsala University. Lichuan Wu is supported by the Swedish Research Council (project 2012-3902).

Edited by: M. Reckermann

Reviewed by: two anonymous referees

\section{References}

Advancing Reanalysis: Overview of current atmospheric reanalyses, available at: https://reanalyses.org/atmosphere/ overview-current-atmospheric-reanalyses\#ERA40, last access: 2 March 2016.

Andersson, T. and Gustafsson, N.: Coast of Departure and Coast of Arrival: Two Important Concepts for the Formation and Structure of Convective Snowbands over Seas and Lakes, Mon. Weather Rev., 122, 1036-1049 1993.

Andersson, T. and Nilsson, S.: Topographically Induced Convective Snowbands over the Baltic sea and Their Precipitation Distribution, Weather Forecast., 5, 299-312, 1990.

Dieterich, C., Schimanke, S., Wang, S., Väli, G., Liu, Y., Hordoir, R., Axell, L., Höglund, A., and Meier, H. E. M.: Evaluation of the SMHI coupled atmosphere-ice-ocean model RCA4_NEMO, Rep. Oceanogr. 47, 1-60, 2013.

Dubé, I.: From $\mathrm{mm}$ to $\mathrm{cm}$... Study of snow/liquid water ratios in Quebec, available at: http://www.meted.ucar.edu/norlat/ snowdensity/from_mm_to_cm.pdf (last access: 28 May 2016), 2003.

ECMWF: Marine, available at: http://www.ecmwf.int/en/research/ modelling-and-prediction/marine, last access: 9 February 2016.

Evans, M. S. and Wagenmaker, R. B.: An examination of an intense west-east oriented lake-effect snow band over southeast Lower Michigan, Natl. Weather Dig., 24, 67-78, 2000.

Holroyd, E. W.: Lake-Effect Cloud Bands as Seen From Weather Satellites, J. Atmos. Sci., 28, 1165-1170, doi:10.1175/15200469(1971)028<1165:LECBAS>2.0.CO;2, 1971.

IPCC: Climate Change 2014: Synthesis Report, Geneva, available at: http://www.ipcc.ch/pdf/assessment-report/ar5/syr/SYR_ AR5_FINAL_full_wcover.pdf (last access: September 2016), 2015.

Janssen, P.: The Interaction of Ocean Waves and Wind, Cambridge University Press, available at: https://books.google.com/books? $\mathrm{hl}=\mathrm{en} \& \mathrm{lr}=\& \mathrm{id}=\mathrm{Rb} 0 \mathrm{fRcrTiBUC} \&$ pgis $=1$ (last access: 9 February 2016), 2004.

Jones, C. G., Samuelsson, P., and Kjellstrom, E.: Regional climate modelling at the Rossby Centre, Tellus A, 63, 1-3, doi:10.1111/j.1600-0870.2010.00491.x, 2011.

Kelly, R. D.: Mesoscale Frequencies and Seasonal Snowfalls for Different Types of Lake Michigan Snow Storms, J. Clim. Appl. Meteorol., 25, 308-312, 1986. 
Laird, N. F., Kristovich, D. A. R., and Walsh, J. E.: Idealized Model Simulations Examining the Mesoscale Structure of Winter Lake-Effect Circulations, Mon. Weather Rev., 131, 206-221, doi:10.1175/1520-0493(2003)131<0206:IMSETM>2.0.CO;2, 2003.

Madec, G. and the NEMO team: NEMO ocean engine, NEMO ocean engine, Note du Pole de modélisation de l'Institut PierreSimon Laplace, France, No. 27, ISSN: 1288-1619, available at: http://eprints.soton.ac.uk/64324/ (last access: September 2016), 2012.

Mazon, J., Niemela, S., Pino, D., Savijarvi, H., and Vihma, T.: Snow bands over the Gulf of Finland in wintertime, Tellus A, 67, 1-14, 2015.

MODIS: Atmosphere, available at: http://modis-atmos.gsfc.nasa. gov/IMAGES/, last access: August 2016.

Nikulin, G.: Regional Climate Modeling Results and Ensemble using RCA4, RICCAR, Fifth Expert Gr. Meet., 11-12 December 2013 .

Niziol, T. A.: Operational Forecasting of Lake Effect Snowfall in Western and Central New York, Weather Forecast., 2, 310-321, doi:10.1175/1520-0434(1987)002<0310:OFOLES>2.0.CO;2, 1987.

Niziol, T. A., Snyder, W. R., and Waldstreicher, J. S.: Winter weather Forecasting throughout the Eastern United States. Part IV: Lake Effect Snow, Weather Forecast., 10, 61-77, 1995.

NOAA: Optimum Interpolation Sea Surface Temperature (OISST), Natl. Centers Environ. Inf. Former. known as Natl. Clim. Data Cent., available at: http://www.ncdc.noaa.gov/oisst, last access: 21 March 2016.

Rutgersson, A., Nilsson, E. O., and Kumar, R.: Introducing surface waves in a coupled wave-atmosphere regional climate model: Impact on atmospheric mixing length, J. Geophys. Res. Ocean., 117, C00J15, doi:10.1029/2012JC007940, 2012.

Savijärvi, H. I.: Cold air outbreaks over high-latitude sea gulfs, Tellus, Ser. A Dyn. Meteorol. Oceanogr., 64, 1-11, doi:10.3402/tellusa.v64i0.12244, 2012.
Savijärvi, H.: Cold air outbreaks along a non-frozen sea channel: effects of wind on snow bands, Meteorol. Atmos. Phys., 127, 383-391, doi:10.1007/s00703-015-0370-8, 2015.

SMHI: Snökanon från havet, available at: http://www.smhi.se/ kunskapsbanken/meteorologi/snokanon-fran-havet-1.13740 (last access: 4 February 2016), 2015.

Uppala, S. M., KÅllberg, P. W., Simmons, A. J., Andrae, U., Bechtold, V. D. C., Fiorino, M., Gibson, J. K., Haseler, J., Hernandez, A., Kelly, G. A., Li, X., Onogi, K., Saarinen, S., Sokka, N., Allan, R. P., Andersson, E., Arpe, K., Balmaseda, M. A., Beljaars, A. C. M., Van De Berg, L., Bidlot, J., Bormann, N., Caires, S., Chevallier, F., Dethof, A., Dragosavac, M., Fisher, M., Fuentes, M., Hagemann, S., Hólm, E., Hoskins, B. J., Isaksen, L., Janssen, P. A. E. M., Jenne, R., Mcnally, A. P., Mahfouf, J.-F., Morcrette, J.-J., Rayner, N. A., Saunders, R. W., Simon, P., Sterl, A., Trenberth, K. E., Untch, A., Vasiljevic, D., Viterbo, P., and Woollen, J.: The ERA-40 re-analysis, Q. J. Roy. Meteor. Soc., 131, 29613012, doi:10.1256/qj.04.176, 2005.

Valcke, S.: The OASIS3 coupler: a European climate modelling community software, Geosci. Model Dev., 6, 373-388, doi:10.5194/gmd-6-373-2013, 2013.

Vihma, T. and Brümmer, B.: Observations and modelling of the onice and off-ice air flow over the northern baltic sea, Bound.-Lay. Meteorol., 103, 1-27, 2002.

WAMDI Group, T.: The WAM model - A third generation ocean wave prediction model, J. Phys. Oceanogr., 18, 1775-1810, doi:10.1175/1520-0485(1988)018<1775:TWMTGO>2.0.CO;2, 1988.

Wang, S., Dieterich, C., Döscher, R., Höglund, A., Hordoir, R., Meier, H. E. M., Samuelsson, P., and Schimanke, S.: Development and evaluation of a new regional coupled atmosphereocean model in the North Sea and Baltic Sea, Tellus A, 67, 1-20, doi:10.3402/tellusa.v67.24284, 2015.

Wu, L., Rutgersson, A., Sahlee, E., and Larsén, X. G.: The impact of waves and sea spray on modelling storm track and development, Tellus A, 67, 1-24, doi:10.3402/tellusa.v67.27967, 2015. 